\title{
Maintenance Design and Computer Simulation of A Certain Type of Gear Wheel Reducer
}

\author{
Shuhai Wang ${ }^{1}$, Fenghe Tao ${ }^{1}$, Guibo $\mathrm{Yu}^{1}$, Xujun $\mathrm{Su}^{1}, \mathrm{Xia}_{\mathrm{Tao}}{ }^{2}$ and Zhanjie Yuan ${ }^{1}$ \\ ${ }^{1}$ No.1 Department, Shijiazhuang Mechanical Engineering College, Shijiazhuang, 050003, China \\ ${ }^{2}$ Economy and Trade Department, Shijiazhuang Vocational Technology Institute, Shijiazhuang, 050081, China
}

\begin{abstract}
The gear wheel reducer of self-propelled weapons is the final reduction gear drive in the drive system. Under the same ratio of transmission, using reduction gear can reduce the load of transmission, drive shaft, main reducer, differential mechanism and half shaft, the size becomes smaller and the drive axle can achieve larger space from the ground. The wheel reducer is widely adopted in such vehicle as heavy duty truck, crosscountry vehicle and large industrial and mining vehicles. WS series chassis wheel reducer is the most typical. Therefore it is significant to do research on its oil change and maintenance
\end{abstract}

Keywords-equipment chassis; wheel reducer; maintenance design; computer simulation

\section{BACKGROUND AND SIGNIFICANCE}

Wheel reducers are heavily employed in military equipment for slow increase torsion. With gear load increase of modern vehicles and higher temperature, gear oil in the reduction gear is highly demanding. So it is needed to check and change the oil in the working process.

Although the wheel reducer is widely used, efficient and convenient oil change facility and its maintenance are highly demanding in the process of oil change. The traditional oil change is slow with low efficiency, which can not meet the demands of modern military weapon maintenance. In addition, that dirty oil can not be removed thoroughly is another problem, which leaves risk of wheel reducers during the operation. Therefore, it is demanding both in military maintenance and market to do research on oil maintenance device of the wheel reducer.

\section{INTRODUCTION OF GEAR REDUCTION}

In some preparations, more power is needed but it is slow in the case of higher axle ratio and larger space from the ground. Installed near the gear on the both sides, the second level wheel reducer mechanism in double main reducer is made up with two sets and called wheel reduction gears. Off- road vehicle needs good driving both on the poor roads and off roads with enough space from the ground when it is heavily loaded. Thus, wheel reducers are needed to install by the sides of the wheels when designing heavy -loaded trucks, and offroad trucks.

\section{THE SHORTAGE OF THE TRADITIONAL OIL CHANGE WAY}

The filler and oil drain hole of 3 WS series chassis wheel reducer are set at the position. The oil spill is in the middle of the wheel edge reducer, as shown in figure 1.

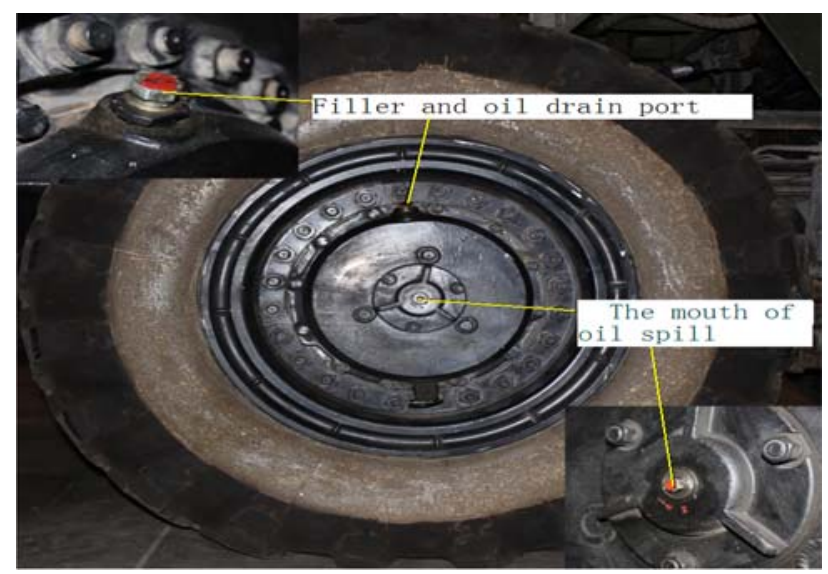

FIGURE I. WHEEL REDUCER

Usual steps of oil drainage for WS series wheel reduce: jack up the wheels with the jack, rotate the wheels drain plug to the right. Oil tank is put out and put it in the mouth plug. Unscrewed spilled oil plug and drain plug hold the drained oil with a container. In the above process, it is slow and the oil can not be drained thoroughly.

\section{DESIGN OF MAINTENANCE EQUIPMENT}

Research on innovative design for oil change of the WS series wheel reducer is as follows: explore the conventional method of oil change and its deficiency and put forward the new program. Determine the main parameters of various components by the demand of oil change of wheel reducer. Then use Solid Works platform for early modeling, create the virtual prototype, analyze various components using Simulation on the basis of the finite element method, FLOW Simulation to optimize the design. The design process is shown in figure 2. 


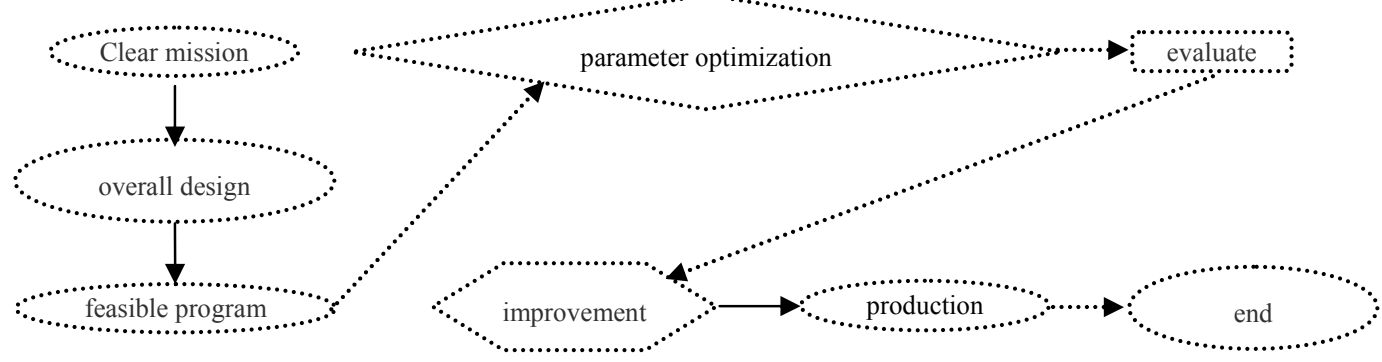

FIGURE II. DESIGN PROCESS

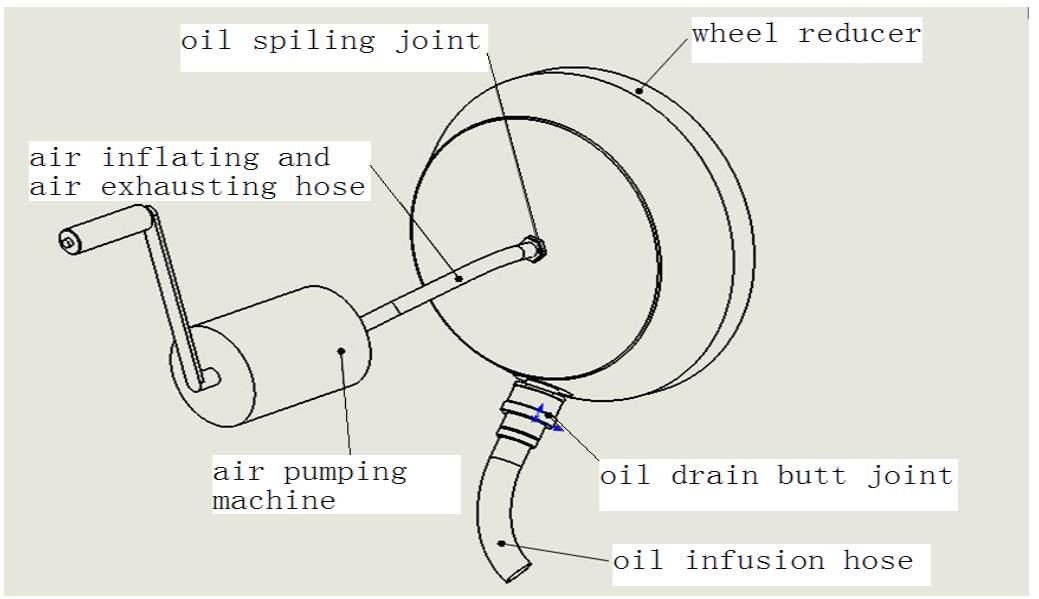

FIGURE III. OIL CHANGE DEVICE PRINCIPLE DIAGRAM

\section{COMPUTER SIMULATION OF MAINTENANCE EQUIPMENT}

\section{A. Analysis Method Overview}

First according to the design, established the 3D model on Solid Works software platform, set model materials, use environmental parameters and build the virtual prototype. Through the mechanical analysis of prototype parts through Solid Works Simulation, correct the unreasonable design details, such as stress concentration, intensity and etc. Then, analyze flow field using Flow simulation, providing a reference for optimized design to improve its current performance.

\section{B. Design Scheme and Principle}

Gear oil of heavy load is of strong tackiness and low fluidity in normal temperature. Through the experiments, it is found that oil stuck on planetary gears is difficult to be removed off in a short time. The un-removed sump oil will pollute the newly infused oil. Therefore, it is quite necessary to design a new device to extract oil thoroughly and infuse oil fast. Due to high oil tackiness and limited oil hole, it is quite slow to adopt traditional way of infusion. According to statistics of traditional oil change, it takes two hours averagely for two persons to remove gear oil for one wheel. Vacuum pumping and pressure oiling are explored in the research. The principle is shown in the following diagram (Figure 3). oil change device is composed of air pumping machine, air inflating and air exhausting hose, oil spilling joint, oil infusion and dumping joint butt, and oil infusion hose.

\section{Mechanical Analysis of Key Parts (Oil Spill Joint for Example)}

As shown in figure 4, oil spill fitting is a thin-wall hole with thread parts. Its function is to connect wheel reducer oil spill mouth and vent hose. It is connected through thread to oil spill mouth. In the process of connection, oil spill joint torque, therefore, statics analysis of reverse parts is needed.

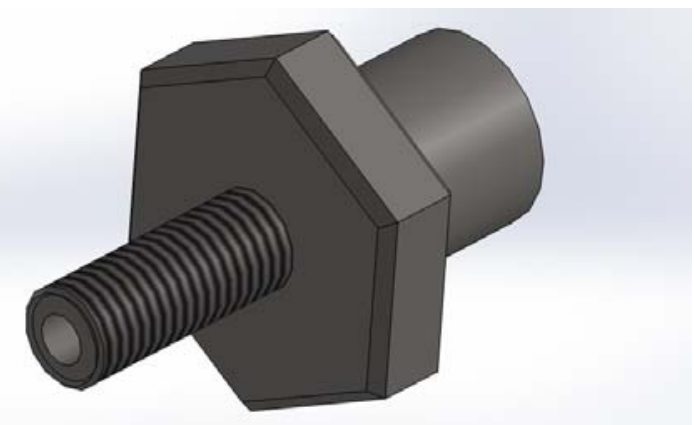

FIGURE IV. OIL SPILL JOINT 3D MODEL

- Set load and fixture

Fixture: type of fixed geometry, fixed surface as shown in figure 5 blue highlight part.

Load: type of applied torque, a value of 1 N.M torque direction and bearing surface as shown in figure 5 blue highlight part of the arrow. load diagram as Figure 5. 


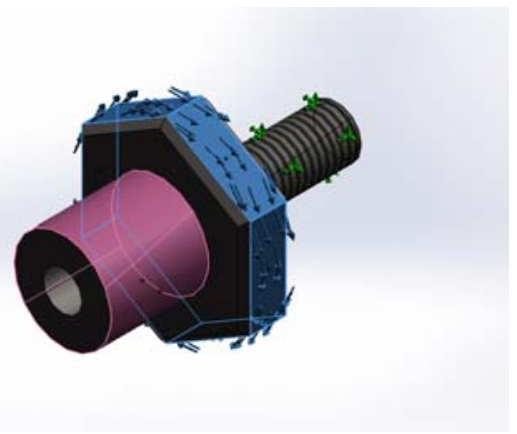

FIGURE V. LOAD DIAGRAM

- The grid information

Grid type: entity grid is used for the grid: a standard grid automatic transition: closed including grid automatically ring: closed. Jacobi is 4 point. Unit size: $0.943968 \mathrm{~mm}$,tolerance: $0.0471984 \mathrm{~mm}$. grid chart as Figure 6 .

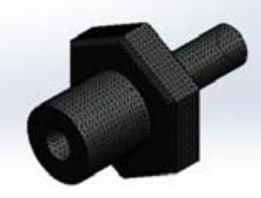

\section{FIGURE VI. GRID CHART}

- Numerical example results: VON Mises stress distribution: as shown in figure.7, the minimum is $0.00960087 \mathrm{~N} / \mathrm{m}^{\wedge} 2$, the maximum is $1.44177 \mathrm{e}+008$ $\mathrm{N} / \mathrm{m}^{\wedge} 2$.

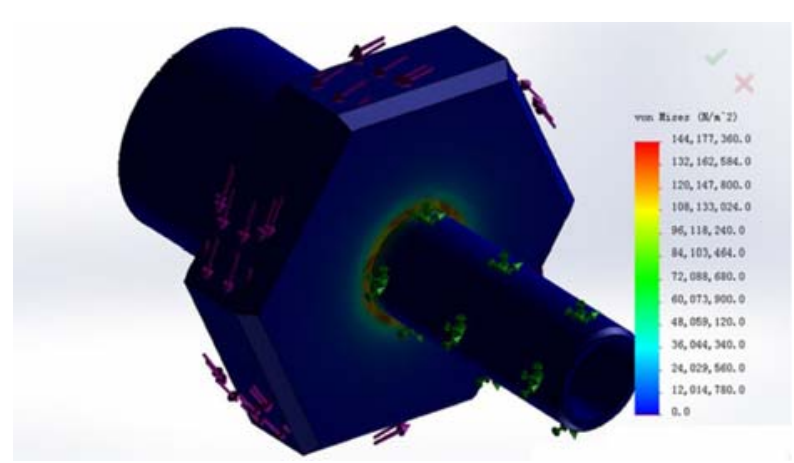

FIGURE VII. VON MISES STRESS DISTRIBUTION NEPHOGRAM

\section{Results Analysis and Optimization}

Results: The VON Mises stress nephogram red part is the weakest part of the whole parts, characterized by stress concentration, low safety factor. Because the parts will be repeatedly disassembled at the edge of the wheel gear reducer on the oil spill, they need to be optimized to strengthen the weak parts. By VON: VON Mises stress nephogram, the weak part is thin-wall hole and is at the junction of six prism. When the load is $3 \mathrm{n}$. m, the maximum stress of the weak part is
$411868832 \mathrm{~N} / \mathrm{m}^{\wedge} 2$, exceeding the material yield strength. The size of thin wall part is $\Phi 8$ outer diameter, $6 \Phi$ inner diameter and $1 \mathrm{~mm}$ wall thickness. It can be improved with thickening thin wall. Take control variable method. Set conditions unchanged of example of material properties, load and fixture and grid properties. Only change the wall thickness of the thin wall pipe: outer diameter $\Phi 8$ inner $\Phi 4$ wall thickness $2 \mathrm{~mm}$.

\section{REFERENCES}

[1] Ren-xi Hu \& Shi-ting Kang. Solid Works 2012 finite element, the virtual prototype and flow field analysis from entry to master [M], mechanical industry publishing house, 2012, 7

[2] Ming-xin He \& Ke-qiang Qian, Machinery Drawing [M], 2004,01 Higher Education Press

[3] Heng Sun, Zuo-mo Chen \& Wen-jie Ge, Mechanical Principle [M], 2006, 05 Higher Education Press

[4] Nai-shi Cheng, Reducer and Transmission Design and Choose Manual [M], Mechanical Industry Publishing House, 2007

[5] Liang-gui Pu \& Ming-gang-Ji, Machine Design [M], 2004,05 Higher Education Press 